\section{Measures to support a safer drug supply}

Tyndall's CMAJ commentary regarding safer supply, namely pharmaceutical alternatives to the poisoned drug supply fueling the overdose crisis, describes the roots of the overdose crisis and calls for a clear strategy to scale up safer supply prescribing. ${ }^{1}$ Addressing barriers to prescribing, coupled with the decriminalization of drugs, is essential to the success of this approach.

Tyndall discusses how the provision of safer supply by physicians has been met with reluctance, and that prescribing rates are too low to positively affect the overdose crisis. ${ }^{1}$ This is partly because of prescription review programs by regulatory colleges, with perceived inappropriate prescribing being grounds for reprimand. Federal Minister of Health Patty Hajdu released a letter calling on colleges to support clinicians and increase access to safer supply. ${ }^{2}$ As the minister points out, important measures to prevent opioid overprescribing must be weighed against the need to prescribe pharmaceutical alternatives. Supporting clinicians to prescribe without fear of reprisal may affect access to safer supply.

Prescribing rates, however, even for evidence-based therapies for opioid use disorder, are low among physicians, indicating that the widespread adoption of safer supply prescribing will be a challenge. ${ }^{3}$ A practitioner-led model requires engagement from more clinicians, with access to a wider array of opioid formulations, such as liquid hydromorphone and diacetylmorphine. Recently, British Columbia implemented a public health order that expanded prescribing of con- trolled substances by registered nurses. ${ }^{4}$ This is a major step for increasing access to safer supply.

In Ontario, safer supply programs have been in place for up to 5 years, showing preliminary results of decreased rates of overdose and infection, improvements in chronic disease management and decreases in illegal activities to fund illicit drug purchase. ${ }^{5}$ These programs are creating compelling evidence that many of the harms of illicit drug use are in fact related to the prohibition of these substances and our societal response to their use. ${ }^{5}$ Prime Minister Justin Trudeau specifically stated that the decriminalization of drugs is not being considered and that safer supply is the government's key priority for addressing the overdose crisis. ${ }^{6}$ However, criminalizing drugs and the people who use them disproportionately affects poor and racialized groups, thereby undermining efforts made to improve access to health care services, including safer supply. Government officials should look to decriminalization as part of a plan to support expanded access to safer supply. This would require legislative change and coordination among government agencies, as has been done in response to coronavirus disease 2019 (COVID-19).

Swift and decisive action has been crucial to Canada's success in limiting the spread of COVID-19. The same emphatic response is needed now to combat the overdose crisis. As we await a large-scale public health model of safe supply, clinicians must be supported by regulatory colleges to prescribe safer opioid alternatives in tandem with the decriminalization of drugs and the people who use them.

\section{Andrea Ryan MD}

International Collaborative Addiction Medicine research fellow and addiction medicine physician, BC Centre on

Substance Use, Vancouver, BC

\section{Andrea Sereda MD}

Family physician, London

Intercommunity Health Centre, London, Ont.

\section{Nadia Fairbairn MD MHSC}

Assistant professor, Department of Medicine, University of British Columbia, Vancouver, BC

Cite as: CMAJ 2020 December 7;192: E1731. doi: 10.1503/cmaj.77303

\section{References}

1. Tyndall M. A safer drug supply: a pragmatic and ethical response to the overdose crisis. CMAJ 2020;192:E986-7.

2. Hajdu P. Letter from the Minister of Health regarding treatment and safer supply. Ottawa: Government of Canada; 2020 Aug. 24.

3. Guan Q, Khuu W, Spithoff S, et al. Patterns of physician prescribing for opioid maintenance treatment in Ontario, Canada in 2014. Drug Alcohol Depend 2017;177:315-21.

4. British Columbia Ministry of Health, Office of the Provincial Health Officer. Registered nurse and registered psychiatric nurse public health pharmacotherapy. Provincial health officer's order. Available: www2.gov.bc.ca/assets/gov/ health/about-bc-s-health-care-system/office -of-the-provincial-health-officer/covid-19/covid -pho-order-rn-pharmacotherapy.pdf (accessed 2020 Sept. 23).

5. Bonn M, Felicella G, Johnson C, et al. COVID-19, substance use, and safer supply: clinical guidance to reduce risk of infection and overdose [webinar]. Vancouver: British Columbia Centre on Substance Use; 2020.

6. Woo A. Trudeau says focus is on safe supply, not decriminalization as overdose deaths spike. The Globe and Mail [Toronto]. Available: www. theglobeandmail.com/canada/british-columbia/ article-trudeau-says-focus-is-on-safe-supply-not -decriminalization-as/ (accessed 2020 Sept. 2).

Competing interests: None declared. 